Article

\title{
Investigating Sustainable Commuting Patterns by Socio-Economic Factors
}

\author{
Woo Jang *, Fei Yuan (D) and Jose Javier Lopez
}

Citation: Jang, W.; Yuan, F.; Lopez,

J.J. Investigating Sustainable

Commuting Patterns by Socio-

Economic Factors. Sustainability 2021,

13, 2180. https://doi.org/10.3390/

su13042180

Academic Editor: Byungyun Yang

Received: 1 February 2021

Accepted: 14 February 2021

Published: 18 February 2021

Publisher's Note: MDPI stays neutral with regard to jurisdictional claims in published maps and institutional affiliations.

Copyright: (c) 2021 by the authors. Licensee MDPI, Basel, Switzerland. This article is an open access article distributed under the terms and conditions of the Creative Commons Attribution (CC BY) license (https:// creativecommons.org/licenses/by/ $4.0 /)$.
Department of Geography, Minnesota State University, Mankato, MN 56001, USA; fei.yuan@mnsu.edu (F.Y.); javier-jose.lopez-jimenez@mnsu.edu (J.J.L.)

* Correspondence: woo-suk.jang@mnsu.edu; Tel.: +1-507-389-1466

\begin{abstract}
This research aims to analyze how modes of transportation differ according to socioeconomic factors in an urban space. The study area is Ramsey County, the most densely populated county in Minnesota. The primary data used were from the recent 2012-2016 Census Transportation Planning Products (CTPP). We performed regression models to identify the relationship between mode of transport and socio-economic variables, and further analyzed disaggregate trip data to provide a more realistic evaluation of commuting patterns by use of multiple variables in combination. The research found that sustainable commuting patterns correlated significantly with both poverty and minority group status, but bore no significant relationship to older workers. Additionally, there was a significant correlation between commuting alone by car with both minority group status and older workers, but not with poverty. This research also confirmed that the sustainable commuting patterns of the working poor were mostly located in the downtown area, while causes of low-income workers driving alone typically involved much longer commutes to and from points throughout the study area, suggesting that more efficient commutes are a significant quality of life factor for the urban poor when evaluating residential and employment opportunities in the central city.
\end{abstract}

Keywords: CTPP; disaggregate trip; GWR; sustainable commuting

\section{Introduction}

Commuting patterns play an essential role in understanding various aspects of spatial mismatch between jobs and housing. Previous research has typically focused on how commuting patterns differ by gender, income, race, job, and mode of transport [1-3]. Antipova (2020) pointed out that low-income workers had shorter commutes, on average, than most commuters [1]. Kim et al. (2012) explored the variations in job access by gender and occupation and found that men commuted further than women in most job categories. By contrast, female workers with highly-skilled professional jobs had longer commutes than male workers in general, indicating that occupational impact could outweigh gender [2]. Jang and Yao (2014) examined commuting trips in relation to ethnicity between 1990 and 2008, and found that Latino commuting patterns had increased significantly over time, expanding from the central city into the inner suburbs [3].

Due to an increase in traffic problems (e.g., congestion, accidents, and pollution), the terminology of green commuting - or sustainable commuting — has received considerable scholarly attention, emphasizing the need to reduce greenhouse gas emissions, diminish air pollution, and consider commuter health benefits. Besides air contamination, heavy dependence on cars produces noise [4]. Recent research has identified strategies for achieving sustainability goals to protect our planet, while improving our quality of life. These strategies include: (a) increasing urban green space; (b) improving accessibility to public transport; (c) reducing pollution through the use of public transport and vehicles with zero- or low-carbon emissions [5,6]. A green (sustainable) commute represents any transportation mode that does not involve a single passenger driving alone to work [7]. According to Bergman and Bergman (2019), walking is the most sustainable form of 
commute, followed by cycling, then public forms of transportation, such as buses, trams, and especially trains [8]. The American Public Transportation Association (2017) found that: (a) African American riders were the largest single group to use public transport; (b) about $71 \%$ of riders were employed; (c) women represented the majority of transit riders compared to their male counterparts [9].

This research aims to uncover the relationships between various modes of transport and socio-economic factors using the recent 2012-2016 Census Transportation Planning Products (CTPP) data. A better comprehension of the reasons behind commuting decisions can help policy makers design more effective policies regarding commuting options [10]. First, both the global ordinary least square (OLS) regression and local geographically weighted regression (GWR) models were performed to discern the spatial relationship between a dependent variable (sustainable commuting vs. driving alone by car) and a set of independent variables (poverty, minority status, older workers). Second, by applying an information minimization (IM) model, we estimated commuting trips by multi-categorical factors (e.g., sustainable commuting by the working poor vs. driving a car alone by the working poor), allowing us to investigate the spatial characteristics of activities over space in greater detail.

This study is significant in its contribution to our understanding of the spatial dynamics of trip patterns by subgroups. No such trip data by subgroups is available in CTPP, which is widely used in transport analysis. The current aggregate trip data can predict overall trip patterns, but may be misleading if the spatial dynamics of commuting patterns (e.g., sustainable commuting by the working poor) are of concern. By applying disaggregated trip data, transportation planners and policymakers can make better decisions to cope with urban commuting problems (e.g., traffic congestion, inadequacy of pubic transport, and accidents) in U.S. metro areas.

The remainder of this paper is structured as follows: Section 2 reviews the relevant literature related to sustainable commuting and disaggregate commuting patterns. Section 3 presents the methodologies used, including the regression (OLS and GWR) and IM models. Section 4 presents the results of sustainable transport by socio-economic factors. Section 5 provides the discussion of the main findings as well as the strengths and limitations of our study. Section 6 concludes our study with its implications for future research.

\section{Literature Review}

Sustainable commuting (SC) has been commonly defined as environmentally friendly modes of travel, including public transport (bus, tram, subway, light rail), walking, cycling, and carpooling. A subgroup of SC modes, which includes walking and cycling to work, is known as active commuting (AC). The major reasons for promoting AC include benefits to health, public finance, climate change, social connections, and labor productivity. The literature shows that greater SC, especially AC, is associated with higher levels of well-being and convenience $[7,11-13]$. Furthermore, as a specific mode of sustainable commuting, researchers have found that commuting by carpool was not habitual for workers, and that socializing was the main reason given for commuting by carpool [14].

Based on the theory of planned behavior (Ajzen, 1991), the choice of travel mode or behavior is mainly determined by intentions, which are predicted by attitudes, subjective norms, and perceived behavior control [15]. Other factors, such as limited skills, lifechances, environmental concerns, population density, and other conditions, also influence decisions to adopt SC [7,16-19].

Song et al. (2017) found that urban residents' public transport choices in 35 major cities in China were positively associated with built-up areas and commuting times [20]. Reductions in crowding on public transportation vehicles have proven to be a much more crucial factor for attracting car users to shift to public transit than cost and travel time in Shanghai, China [21]. In a recent study, Liu et al. (2020) noted that age, gender, and marriage indirectly influenced the choice of commute mode, while the cost of travel mode had little effect. They further indicated that the required number of transfers and the 
distance of the nearest transport stations were the main factors that restrict commuters from choosing public transport in China [22].

Higher-income and more expensive housing are associated with a lower tendency to walk, cycle, or use public transportation, while these modes of transportation have a higher rate of usage in lower-income tracts in the U.S. [7,23]. In higher-income neighborhoods, features of the physical environment, such as favorable climate, are more important in encouraging the adoption of SC [7]. Car ownership, race, gender, education, and other neighborhood features also affect the use of non-motorized alternatives. In the U.S. metro cities, the impact of the job-worker mismatch on the commuting time is more significant in the suburbs than in city centers, indicating that suburban areas may need to be prioritized with respect to transportation policy in order to promote SC for the metropolitan region [24].

Oviedo and Guzman (2020) confirmed that in Latin America low- and middle-income areas were more accessible than high-income areas by both public and private transport [25]. Levin (2019) reported that in Sweden, public transport was the standard means of transportation for younger people, while older people were more often car-dependent. This study found a higher rate of confidence in public transport in large and mediumsized Swedish cities, in contrast to a greater desire for car ownership among small city residents [26]. Likewise, Delbosc and Currie (2011) explored the spatial differences in measures of transport disadvantage, social exclusion, and well-being in a survey of inner metropolitan, outer suburban, urban fringe, and regional areas of Victoria, Australia. They found significant differences in mobility and car reliance between geographic locations, with car dependence at its peak in fringe Melbourne. Links between transport disadvantage and social exclusion were weak in their study, while links between transport disadvantage and well-being were strongest in the regional sample [27].

Previous studies have used various methods to examine the choice of travel modes. For example, the global ordinary least squares (OLS) models have been widely adopted to analyze sustainable commuting behavior $[7,20]$, whereas the local GWR models have been used to estimate the annual average daily traffic and spatial variations at different locations [28] and factors affecting public transportation usage rate [29]. Different types of logit models have been applied to understand factors influencing commuters' travel behaviors [30-32]. Additional methods, such as cluster analysis, random forest modeling, random regret minimization, graph theory, and the information minimization (IM) model, have also been used to study travel mode choice [2,3,33-36]. Moreover, multi-criteria decision-making (MCDM) methods with various mathematical approaches have been used for mobility analyses, in which a number of decision criteria were defined [14].

\section{Methodologies}

\subsection{Study Area}

Over the past decade, Minnesota's population has grown by approximately $6 \%$, a rate similar to the national population growth, while faster than most other Midwestern states. Most of the state's population growth occurred in the Twin Cities Metropolitan Area (TCMA), which grew by about $9 \%$ due to a higher rate of natural increase and higher domestic and international migration [37].

The study area, Ramsey County, is the most densely populated county in Minnesota and home to the state capital of St. Paul (See Figure 1). Featuring the smallest land area of any county in the Twin Cities Metropolitan Area (TCMA) (43,900 ha, or 5.7\% of the total) and the second-largest TCMA county population (18\% of total), Ramsey County's population increased from 509,000 in 2010 to 559,000 in 2020, an increase of nearly $10 \%$. About two-thirds of the county's population is white, with Asians or Pacific Islanders (14.2\%), Blacks or African Americans (11.8\%), and Hispanics or Latinos (7.5\%) making up the vast majority of the remaining population. The estimated median household income in 2018 was USD 62,304 with $14.7 \%$ of the population classified as poor. The workforce was divided between younger workers (ages 29 or younger), middle workers (ages 30-54), and 
older workers (ages 55 or older), who comprise $26.9,51.9$, and $21.2 \%$ of the population, respectively [38].

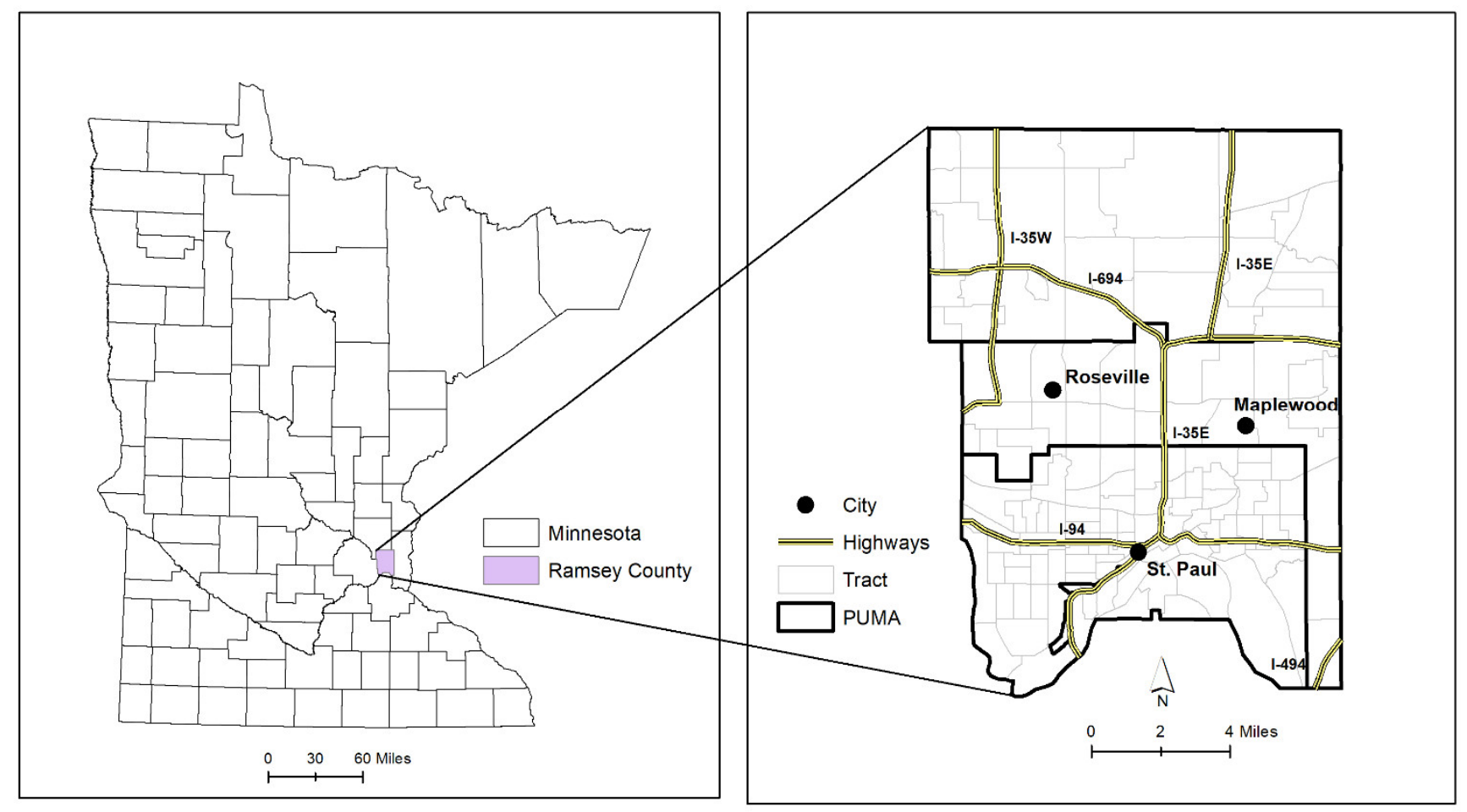

Figure 1. Ramsey County in Minnesota.

County land use includes residential ( $43 \%$ of the total land), park, recreational or preserved land $(14 \%)$, open water $(9 \%)$, undeveloped land $(8 \%)$, institutional $(6 \%)$, industrial and utility (5\%), retail and other commercials (4\%), and major highways (4\%) [39]. Due to the lack of vacant land for expansion, Ramsey County's growth is mainly due to an increase in the intensity of existing built-up area development [40]. The major interstate highways that cross Ramsey County are Interstate 35 (I-35W and I-35E two routes), Interstate 94, and Interstate 494, as well as the auxiliary Interstate 694 (I-694). Several US highways also serve Ramsey County, such as US 10, US 52, and US 61, Minnesota state highways (MN 36 and MN 51), as well as over 264.1 miles of County State Aide Highways and 21,031 miles of county roads [41,42]. The Mississippi River winds through the southern part of the county, providing the source of most of the drinking water supply for Ramsey County and providing the community with a source of transportation, recreation, and energy.

\subsection{Data}

The Census Transportation Planning Products (CTPP) serves as the major data source for studies of urban commuting. This data series releases data aggregated at a variety of geography scales (e.g., census tract, traffic analysis zone, county) for a number of different years (e.g., 1990, 2000, 2006-2010, 2012-2016), providing invaluable information such as demographic, social-economic variables, and commuting flows. The CTPP data consist of three parts: CTPP1 (place of residence), CTPP 2 (place of work), and CTPP 3 (commuter flows between residence and workplace). The CTPP provides a special set of tables (198 in total) from the American Community Survey (ACS) data, including 116 tables in Part 1, 57 tables in Part 2, and 25 tables in Part 3, respectively. The 2012-2016 CTPP data at the Census Tract level were the primary data used in this research, which included a total of 137 Census Tract zones. The data were obtained from the website of the American Association of State Highway and Transportation [43]. 


\subsection{Method}

This research conducted a comprehensive spatial analysis of commuting patterns and investigated how the selected transportation modes (i.e., sustainable commuting and driving alone by car) differed by socio-economic/demographic factors (e.g., poverty, race, age). First, we performed both an ordinary least square (OLS) regression and a geographically weighted regression (GWR) to evaluate relationships between dependent and independent variables. The OLS regression is a global model that provides one equation to represent the entire dataset. In contrast, the GWR is a local model to fit a regression equation to every feature in the dataset, taking local changes into account and calculating the unique coefficients for each location [44]. Second, we adopted an information minimization (IM) model, which predicts commuting flows by the mode of transportation (MOT) as well as those of the working poor, and investigates where sustainable commuting patterns by workers classified as poor exist in the study area.

Step 1: OLS and GWR Regressions

Ordinary least square (OLS) is a linear regression that models a dependent variable based on several independent variables. First, we applied an OLS regression model to evaluate the relationships between a set of independent variables (i.e., poverty, minority group status, and older workers) and dependent variables (i.e., sustainable commuting and drive alone). To deal with OLS, a dependent variable should be in a normal distribution and independent variables should not be significantly correlated with one another. OLS reports coefficients, $t$ values, and R-squared (coefficients of determination), respectively. $\mathrm{R}$-squared is used to indicate the goodness of fit. The value of R-squared ranges from 0 (indicating a poor fit) to 1 (indicating a good fit). For instance, the large value of R-squared suggests that two variables are strongly related. The equation of the OLS is as follows:

$$
y_{i}=\beta_{0}+\sum \beta_{k} x_{i k}+\varepsilon_{i}
$$

where $y_{i}$ is the dependent variable, $\beta_{k}$ is the coefficients, $x_{i k}$ is the independent variables, and $\varepsilon_{i}$ is the error term.

Next, we used a geographically weight regression (GWR) model to explore spatial variations in the relationship between variables. The GWR model extends the OLS model to estimate a location-specific relationship between a set of dependent and independent variables. It shows how variable values differ across a spatial area. GWR yields local coefficients, local $t$ values, and local $R$-squared that examine their spatial variations on the map. The GWR results can be compared to the OLS results with adjusted R-squared and Akaike information criterion (AIC). AIC is an estimate of the out-of-sample prediction error, which evaluates the relative quality of the statistical model for a given data set. The rule of thumb is that lowering the AIC by 3 is considered a better improvement. In this study, we focused on the CTPP 2 (workplace) data for spatial regression. The equation of the GWR model is described as:

$$
y_{i}=\beta_{0}\left(u_{i}, v_{i}\right)+\sum \beta_{k}\left(u_{i}, v_{i}\right) x_{i k}+\varepsilon_{i}
$$

where definitions of $y_{i}, \beta_{k}, x_{i k}, \varepsilon_{i}$ are the same in Equation (1), and $\left(u_{i}, v_{i}\right)$ is the coordinates of $i$.

Step 2: Information Minimization (IM)

The analysis of commuting patterns (known as journey-to-work) in the past has typically dealt with commuters in general in metropolitan areas, without analyzing the commuting patterns of various subgroups of the population $[45,46]$. This is a reflection of the CTPP 3 (commuter flows) data, which is aggregated at various levels of spatial granularity for all working populations. Thus, no such commuting trips data are available for subgroups (e.g., as categorized by gender, income, race/ethnicity). This aggregated approach is appropriate for understanding the overall trip patterns. However, commuting patterns differ markedly from factors such as income, race, and gender. To fill in this gap, researchers developed an information minimization (IM) method to estimate 
disaggregate trip data in a way that is maximally consistent with the known data from CTPP 1 and 2 [2,3,47]. By applying the IM model, researchers can achieve a more in-depth understanding of the spatial dynamic of disaggregated urban commuting patterns in U.S. metro areas.

The IM is based on a trip distribution model to estimate the number of trips between each origin and destination zone. In the IM model shown in Equation (1), each unknown trip between the origin (e.g., home) and destination (e.g., workplace) is estimated from known information such as origin (CTPP 1), destination (CTPP 2), and distance friction factors (i.e., distance and time) that are calibrated from the doubly-constrained gravity model. Balancing factors $\left(A_{i}\right.$ and $\left.B_{j}\right)$ in Equations (4) and (5) are calculated until the two constraints of origin-sum and destination-sum are satisfied (information minimization), meaning that the total number of trips originating in each zone will be equal to the total number of trips ending in each zone. The balancing factors are constrained by balanced home-base trip production in Equation (4) and workplace-based trip attraction in Equation (5). As a result, by matching the $k$ th subgroup (e.g., gender, income, race) at both home and work locations, disaggregate trip data are modeled for the subgroup.

This research extends the IM model to further investigate trip data by mode of transport and poverty to analyze the sustainable commuting patterns of the working poor in the study area, in comparison to the patterns of drive alone commuting by the working poor. Below is the information minimization (IM) equation used to analyze the sustainable commuting patterns of the working poor.

$$
T_{i j}^{k}=A_{i}^{k} O_{i}^{k} B_{j}^{k} D_{j}^{k} \exp \left(-\beta^{k} c_{i j}\right)
$$

where

$$
\begin{aligned}
& A_{i}^{k}=B_{j}^{k} D_{j}^{k} \exp \left(-\beta^{k} c_{i j}\right)^{-1} \\
& B_{j}^{k}=A_{i}^{k} O_{i}^{k} \exp \left(-\beta^{k} c_{i j}\right)^{-1}
\end{aligned}
$$

subject to

$$
\begin{aligned}
& \sum_{j} T_{i j}^{k}=O_{i}^{k} \forall_{i} \\
& \sum_{i} T_{i j}^{k}=D_{j}^{k} \forall_{j}
\end{aligned}
$$

In Equations (3)-(7), $T_{i j}$ is the number of trips between zone $i$ (home) and zone $j$ (workplace). $k$ is the index of the subgroup (i.e., sustainable transportation and poverty). $T_{i j}^{k}$ is the total number of commuting trips between spatial zones $i$ and $j$ for the $k$ th subgroup. $A_{i}^{k}$ represents balancing factors for zone $i$ for the $k$ th subgroup. $B_{j}^{k}$ represents balancing factors for destination $j$ for the $k$ th subgroup. $O_{i}^{k}$ is the number of workers in category $k$ from zone $i$. $D_{j}^{k}$ is the number of workers in category $k$ in zone $j . c_{i j}$ is the travel cost (i.e., time) between zone $i$ and zone $j$.

\section{Results}

Table 1 shows the descriptive statistics for dependent/explanatory variables in the workplace (i.e., CTPP 2) in Ramsey County. The mode of transportation (a total of 292,485 workers) in Ramsey County included drive alone by car (78.4\%), sustainable commuting $(16.7 \%)$, and worked at home (4.9\%). Overall, four out of five workers used private cars to commute to workplaces. Sustainable commuting (utilized by a total of 48,918 workers) was divided into seven categories: carpooled (8.5\%), public transport $(4.1 \%)$, bicycle $(1.0 \%)$, walked $(2.5 \%)$, taxicab $(0.1 \%)$, motorcycle $(0.1 \%)$ and other methods $(0.4 \%)$. The percentage of poverty (categorized as below the $100 \%$ poverty level in CTPP 2 ) in Ramsey County was $5.4 \%$ or 15,885 workers, compared minority groups as $21.0 \%$ or 61,410 , and older workers ( 65 and above) as $4.2 \%$ or 12,401 . Note that the federal poverty 
level was USD 24,563 for a family of 4 in 2016 [48]. In CTTP 2 (place of work), the poverty level is divided into three categories: (a) below $100 \%$ of poverty, (b) between $100-149 \%$, and (c) at or above $150 \%$. In this study, we used "below 100\%" poverty category, indicating the poorest group of workers, who made up $5.4 \%$ of the population of 292,485 , a lower percentage than the $14.7 \%$ poverty rate cited above in the discussion of the demographics of Ramsey County.

Table 1. Descriptive statistics for dependent/explanatory variables.

\begin{tabular}{cccccc}
\hline Variable & Min. & Max. & Sum & Mean & Std. Dev. \\
\hline Sustainable commuting & 8 & 7165 & 48,918 & 357.07 & 712.23 \\
Drive alone & 25 & 17,940 & 229,355 & 1674.12 & 2523.82 \\
Poverty & 0 & 1050 & 15,885 & 115.95 & 146.24 \\
Minority group & 0 & 4065 & 61,410 & 448.25 & 586.35 \\
Older worker (65 and above) & 0 & 870 & 12,401 & 90.52 & 121.18 \\
\hline Note: $\mathrm{n}=137$
\end{tabular}

Note: $\mathrm{n}=137$.

Before executing the regression model, we checked the normality of dependent variables (sustainable commuting and drive alone) using Kolmogorov-Smirnov (KS) and Shapiro-Wilk (SW) tests. The SW test is a good candidate if the distribution is asymmetric [49]. Both sustainable commuting and drive alone variables showed asymmetric distribution. Based on the normality tests, neither dependent variables were normalized (positively skewed). By applying a logarithmic transformation, we normalized the dependent variables (i.e., LnSc and LnCar). Table 2 shows the result of the normality test with Kolmogorov-Smirnov and Shapiro-Wilk. Note that LnSC is a normalized sustainable commuting variable, while LnCar is a normalized drive alone variable.

Table 2. Normality test of sustainable commuting and drive alone.

\begin{tabular}{ccccc}
\hline & \multicolumn{2}{c}{ Kolmogorov-Smirnov } & \multicolumn{2}{c}{ Shapiro-Wilk } \\
\hline Variable & Statistic & Sig. & Statistic & Sig. \\
\hline Sustainable Commuting & 0.312 & $0.000^{* * *}$ & 0.388 & $0.000^{* * *}$ \\
Drive alone & 0.268 & $0.000^{* * *}$ & 0.578 & $0.000^{* * *}$ \\
LnSC & 0.066 & 0.200 & 0.985 & 0.126 \\
LnCar & 0.049 & 0.200 & 0.993 & 0.790 \\
\hline
\end{tabular}

Note: $\mathrm{n}=137$; Sig represents significance probability; ${ }^{* * *}(p<0.01)$.

The results of the OLS analysis are reported in Table 3. In Model 1 (sustainable commuting), the $p$-values for poverty and minority group were statistically significant, but they were not significant for older workers. Note that the adjusted R-squared values are measures of model performance, ranging from 0.0 to 1.0, with 1 signifying the strongest relationship between variables. The adjusted $R$-square value was 0.5832 , which means there is a $58.32 \%$ chance that the explanatory variables (poverty, minority, older workers) were directly related to sustainable commuting. The adjusted R-squared value was used for our model to give a more realistic indication of the predictive values, whereas the $\mathrm{R}$-squared always increases when the number of independent variables increases. The $p$-values for minority groups and older workers in model 2 (drive alone) were statistically significant but not significant with respect to poverty. The adjusted R-squared value was 0.5616 , indicating that the explanatory variables explained $56.16 \%$ of the variation in drive alone. Both OLS results indicated that the mode of transportation correlated strongly with socio-economic factors. Workers in poverty and minority groups correlated strongly with sustainable commuting, while older workers and minority groups had a similarly strong correlation with driving alone. 
Table 3. Ordinary least squares (OLS) model's coefficient estimates.

\begin{tabular}{|c|c|c|c|c|}
\hline Model & Variable & Coefficient & T-Statistic & $p$-Value \\
\hline \multirow{4}{*}{$\begin{array}{l}\text { 1. Sustainable commuting } \\
\qquad\left(R^{2}=0.5832\right)\end{array}$} & Constant & 1.9598 & 56.9315 & $0.0000^{* * *}$ \\
\hline & Poverty & 0.0007 & 1.9140 & 0.0578 * \\
\hline & Minority group & 0.0003 & 2.8703 & $0.0048^{* * *}$ \\
\hline & $\begin{array}{l}\text { Older worker } \\
\qquad(65+)\end{array}$ & 0.0005 & 1.1330 & 0.2592 \\
\hline \multirow{4}{*}{$\begin{array}{l}\text { 2. Drive alone } \\
\left(R^{2}=0.5616\right)\end{array}$} & Constant & 2.6352 & 70.3983 & $0.000^{* * *}$ \\
\hline & Poverty & 0.0004 & -1.1473 & 0.2533 \\
\hline & Minority group & 0.0001 & 3.8804 & $0.0001^{* * *}$ \\
\hline & $\begin{array}{c}\text { Older worker } \\
(65+)\end{array}$ & 0.0012 & 2.1324 & $0.0348^{* *}$ \\
\hline
\end{tabular}

Note: $\mathrm{n}=137 ;{ }^{*}(p<0.1),{ }^{* *}(p<0.05),{ }^{* * *}(p<0.01)$.

Both GWR results reported better model performances than the OLS models, with higher adjusted $R^{2}$ values and lower AIC values (see Table 4). In the OLS analysis, the $\mathrm{R}^{2}$ values were 0.5832 (sustainable commuting) and 0.5616 (drive alone), respectively. In comparison, in the GWR analysis, the $\mathrm{R}^{2}$ values were higher at 0.6676 (sustainable commuting) and 0.6771 (drive alone). The AIC values for the OLS were 76.398 (Model 1) and 99.3592 (Model 2), compared to 69.3223 (Model 1) and 81.3361 (Model 2) in the GWR. Note that the model that gives the smaller AIC value by three has a better fit with the actual data. Besides, the GWR also gives the local $R^{2}$ (the model of performance at a local scale) to discern which space is strongly related to the explanatory variables.

Table 4. Comparison between OLS and geographically weighted regression (GWR).

\begin{tabular}{ccccc}
\hline Model & \multicolumn{2}{c}{ OLS } & \multicolumn{2}{c}{ GWR } \\
\hline & $R^{2}$ & AIC & $R^{2}$ & AIC \\
\hline 1. Sustainable Commuting & 0.5832 & 76.3980 & 0.6676 & 69.3223 \\
2. Drive alone & 0.5616 & 99.3592 & 0.6771 & 81.3361 \\
\hline
\end{tabular}

The local R-squared values ranged from 0.51 to 0.73 across the study area for the GWR model using sustainable commuting as the dependent variable (the left panel of Figure 2). The highest local R-squared values of sustainable commuting were present in the downtown area (0.71-0.73), and medium-high local R-squared values (0.66-0.7) were identified in the southeastern and southwestern portions of the study area. In contrast, the lowest local R-squared values $(0.51-0.55)$ of sustainable commuting were present in the northeast and north portions of the area. Evidently, the local $\mathrm{R}^{2}$ value varied inversely with the decreases from the urban central business district (CBD) area, and steadily declined as the location of trip origin moved further from the CBD. For the case of driving along (depicted in the right panel of Figure 2), few variations were found in the local $R^{2}$ values. The highest GWR model associations appeared in the central-western and central northeastern suburban areas of the county.

Based on the previous spatial analysis, poverty was related to sustainable commuting but not to driving alone by car. By applying the IM model, we were able to determine the MOT (i.e., sustainable commuting and driving a car alone) for workers classified as the severe poor. To determine travel cost, this research estimated network-based travel time. For a visual purpose and explanation, we first aggregated commuting patterns at the Public Use Microdata Areas (PUMAs) level, which are statistical geographic areas with a minimum population of 100,000. Ramsey County is divided into four PUMA zones: north (Shoreview, White Bear Lake and New Brighton Cities, PUMA 1301), central/far southeast (Maplewood, Roseville and North St. Paul Cities, PUMA 1302), southeast (St. Paul City, East, PUMA 1303), and southwest (St. Paul City, West, PUMA 1304). Second, we used a 
kernel density to estimate the density of the trips in a neighborhood, thus allowing the efficient visualization of disaggregate commuting flows on the map.
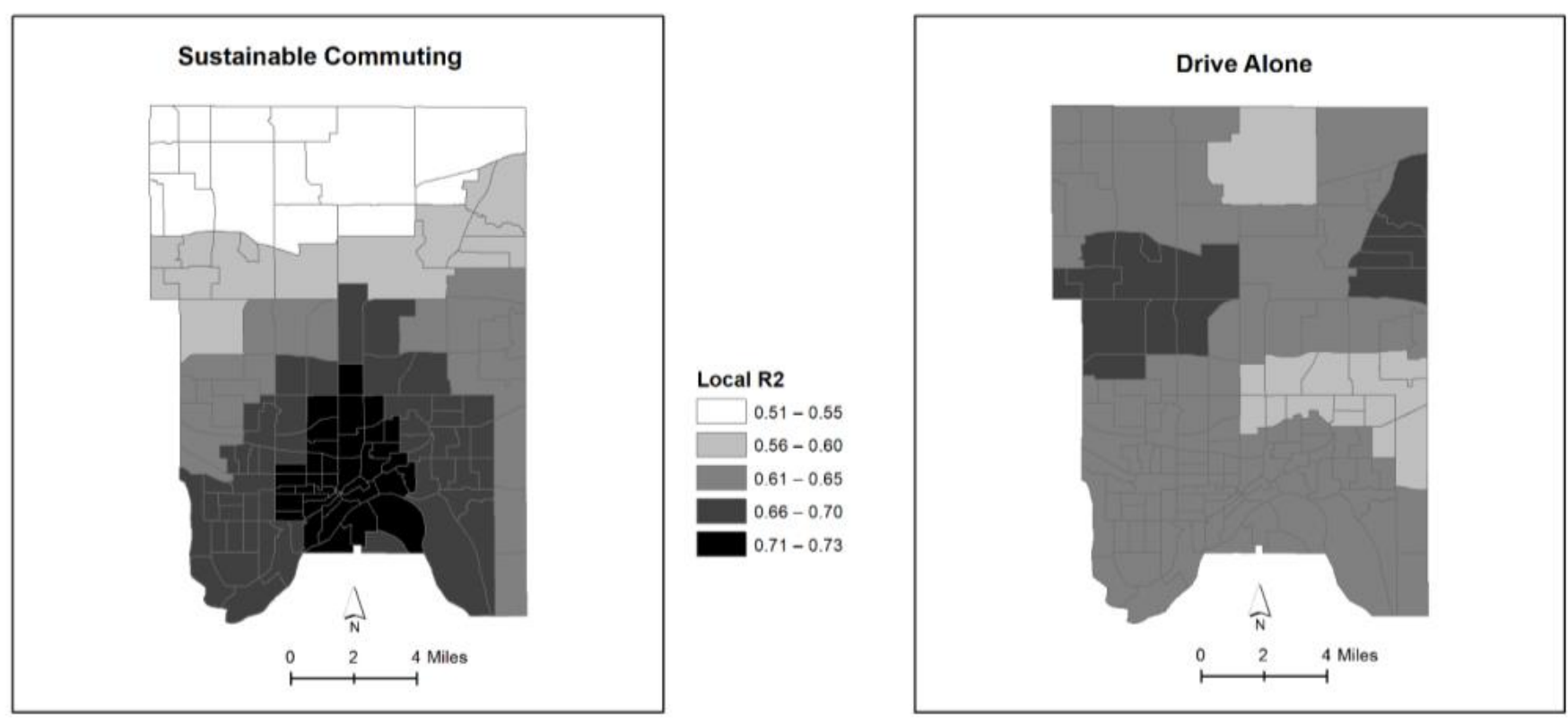

Figure 2. Local R-squared values between sustainable commuting and drive alone by socio-economic factors.

Commuting patterns by MOT and poverty differ over space. Table 5 shows sustainable commuting trips by poverty. The positive effect of poverty on sustainable commuting was the strongest in the southwest and southeast areas (the highest concentration of poverty) and declined toward the north, indicating that low-income people commute from/to workplace mostly in the downtown area (St. Paul), where the most sustainable transport system was available. In contrast, the positive effect of poverty on driving alone was the strongest in the southern areas, but also existed in the northern part of Ramsey County, meaning that the working poor driving alone spanned a much wider space and tended to have longer commute in the study area (See Table 6).

Table 5. Sustainable commuting trips by poverty based on Public Use Microdata Areas (PUMA).

\begin{tabular}{cccccc}
\hline PUMA & $\begin{array}{c}\mathbf{1 3 0 1} \\
\text { (North) }\end{array}$ & $\begin{array}{c}\mathbf{1 3 0 2} \\
\text { (Central) }\end{array}$ & $\begin{array}{c}\mathbf{1 3 0 3} \\
\text { (Southeast) }\end{array}$ & $\begin{array}{c}\mathbf{1 3 0 4} \\
\text { (Southwest) }\end{array}$ & $\sum$ row \\
\hline $\mathbf{1 3 0 1}$ & $120(2.8 \%)$ & $46(1.0 \%)$ & $31(0.7 \%)$ & $45(1.0 \%)$ & $243(5.6 \%)$ \\
$\mathbf{1 3 0 2}$ & $230(5.3 \%)$ & $232(5.3 \%)$ & $181(4.2 \%)$ & $235(5.4 \%)$ & $878(20.1 \%)$ \\
$\mathbf{1 3 0 3}$ & $222(5.1 \%)$ & $206(4.7 \%)$ & $587(13.5 \%)$ & $412(9.5 \%)$ & $1427(32.7 \%)$ \\
$\mathbf{1 3 0 4}$ & $228(5.2 \%)$ & $271(6.2 \%)$ & $368(8.4 \%)$ & $944(21.6 \%)$ & $1812(41.6 \%)$ \\
\hline$\sum$ column & $800(18.4 \%)$ & $754(17.3 \%)$ & $1168(26.8 \%)$ & $1636(37.5 \%)$ & $4359(100.0 \%)$ \\
\hline
\end{tabular}

Note: Values in parentheses indicate percentage.

Table 6. Driving alone trips by poverty based on PUMA.

\begin{tabular}{cccccc}
\hline PUMA & $\begin{array}{c}\mathbf{1 3 0 1} \\
\text { (North) }\end{array}$ & $\begin{array}{c}\mathbf{1 3 0 2} \\
\text { (Central) }\end{array}$ & $\begin{array}{c}\mathbf{1 3 0 3} \\
\text { (Southeast) }\end{array}$ & $\begin{array}{c}\mathbf{1 3 0 4} \\
\text { (Southwest) }\end{array}$ & $\sum$ row \\
\hline $\mathbf{1 3 0 1}$ & $536(12.9 \%)$ & $75(1.8 \%)$ & $32(0.8 \%)$ & $35(0.8 \%)$ & $679(16.3 \%)$ \\
$\mathbf{1 3 0 2}$ & $332(8.0 \%)$ & $283(6.8 \%)$ & $105(2.5 \%)$ & $87(2.1 \%)$ & $807(19.4 \%)$ \\
$\mathbf{1 3 0 3}$ & $312(7.5 \%)$ & $195(4.7 \%)$ & $602(14.5 \%)$ & $222(5.3 \%)$ & $1331(32.0 \%)$ \\
$\mathbf{1 3 0 4}$ & $280(6.7 \%)$ & $161(3.9 \%)$ & $259(6.2 \%)$ & $642(15.4 \%)$ & $1343(32.3 \%)$ \\
\hline$\sum$ column & $1461(35.1 \%)$ & $715(17.2 \%)$ & $998(24.0 \%)$ & $985(23.7 \%)$ & $4160(100.0 \%)$ \\
\hline
\end{tabular}

This research confirmed that poverty correlated strongly with sustainable commuting but less so to driving alone, indicating that the working poor who utilized sustainable 
commuting were generally restricted - in terms of residential choice and job opportunitiesto a relatively small space (mainly the downtown area) in the county (See Figure 3). The sustainable commuting patterns of the working poor were shown to be denser and clustered, in comparison to the commuting patterns of the working poor who drove to work alone. The working poor in Ramsey County suffered from a wide range of transport issues, but access to sustainable commuting was a significant factor for the poor to consider when accessing employment opportunities and residential choices in the central city (i.e., St. Paul).

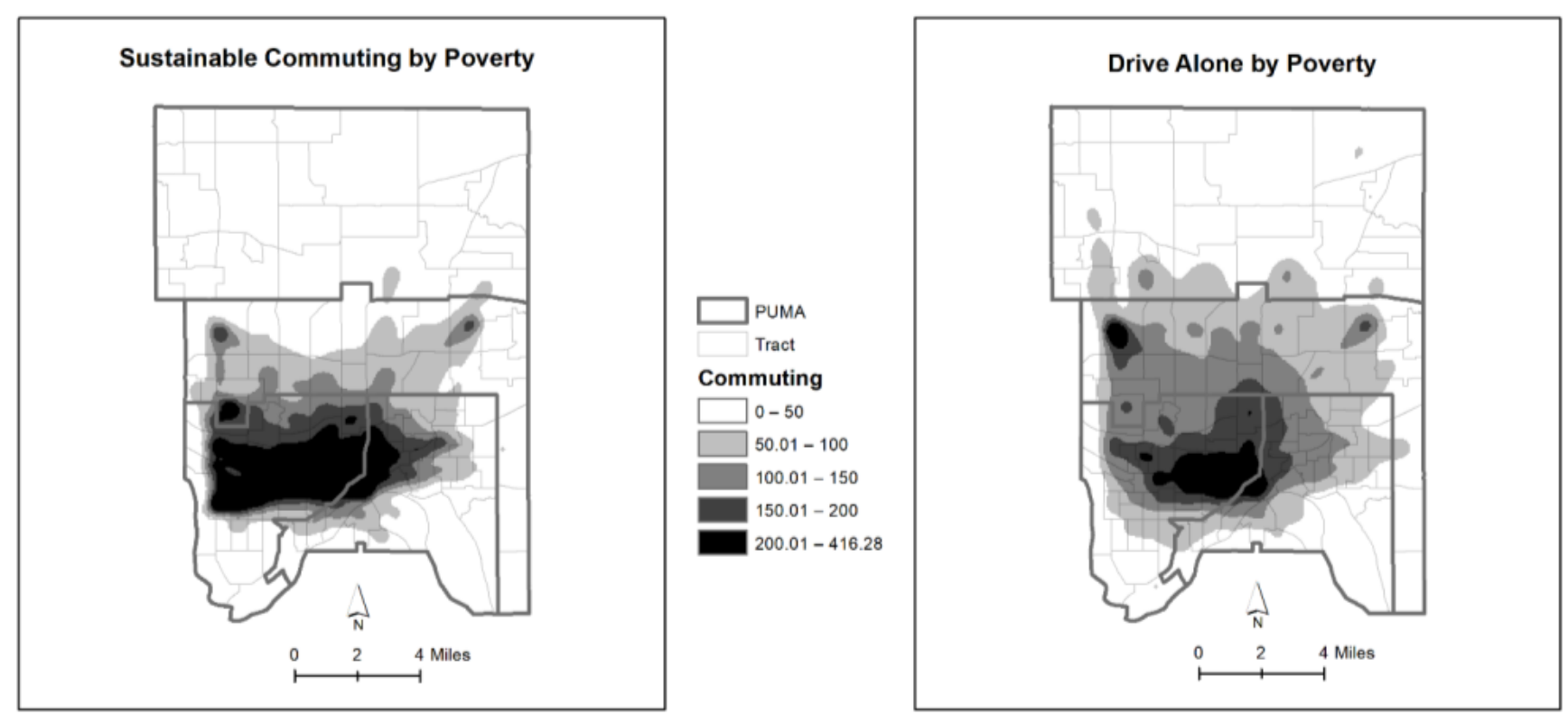

Figure 3. Disaggregate commuting patterns between mode of transportation (MOT) and poverty.

\section{Discussion}

This study investigated commuting trips by subgroups over space. The results of this study corresponded with the findings of previous studies, and demonstrates that (a) low-income people were more highly dependent on sustainable transport than their higher-income counterparts [23], and (b) older people demonstrated a higher rate of driving alone to work than their younger counterparts [26]. In this study, there was a significant correlation between the working poor subgroup and the utilization of sustainable transport, while there was also a strong correlation between the older worker subgroup (65 and above) and commuting by car alone. A correlation was found between minority group status and utilization of sustainable modes of transport, but this was mitigated by income, which had a stronger impact on the choice of transport mode than race. For instance, low-income minority group members relied heavily on sustainable transport, while those of higher income groups heavily relied on driving a car alone. In addition, it was found that the reliance on sustainable transport for commuting significantly impacts the job and housing choices of the working poor in Ramsey County, Minnesota. Through an application of the methods used in this study, transportation planners and policy makers can make informed choices about increasing access to sustainable commuting options for low-income people, as it is clear that access to the transport system plays an important role in shaping the distribution of poverty in a central city or suburban areas. Such results will enhance our understanding of the dynamics of commuting patterns and assist in decision making to address urban challenges.

Traditional trip data visualization uses straight lines between a set of origins and a set of destinations, which presents a significant challenge to visualize which pairs of trips are most likely to cross paths with others. For instance, 1000 census tracts lead to 1,000,000 pairs of trips. This study used a kernel density to visualize commuting patterns by poverty. 
Interactive mapping with a dynamic query will be much realistic to better understand trip data, so researchers will easily be able to investigate which geographic space (e.g., tract, block group, traffic analysis zone) has a high volume of in-and-out commuters. [50]. Interactive mapping of commuting trips with a dynamic query is much more realistic, but beyond the scope of this paper.

Due to the COVID-19 pandemic, commuting patterns have tremendously changed in most U.S. metro areas. At present, average workers prefer to work from home, compared to the past preference of driving alone in a car, which is still the most common means of transportation to work [51]. If continued, these new types of commuting patterns will lead to declines in public transport ridership and funding sources and a reduction in the number of service routes. Low-income people are dependent on public transport for their daily activities [23,52]. The question is how we encourage sustainable commuting ridership for people in need after the pandemic ends. One example is TransitScreen, a Washington DC-based software company that provides real-time transportation arrival data, allowing customers to make better decisions about trips from home to work or vice versa. Another example is JUMP, an electric bicycle sharing system in San Francisco that uses the Uber app to unlock bikes and make payments. These innovative technologies for sustainable transport allow people to make better decisions for their commutes.

\section{Conclusions and Future Outlooks}

Sustainable commuting (or green commuting) plays a vital role in relaxing urban problems such as limited natural resources and increased health concerns. The overall aim of this study is to analyze sustainable commuting of different population groups (i.e., poverty, minority groups, older worker) with the current CTPP data. The results showed that sustainable commuting was heavily related to poverty and minority groups, whereas driving alone by car was closely related to old workers and minority groups. Due to the limitation of the CTPP data, no such disaggregate trip data are available. By applying the IM model, we estimated heterogenous commuting patterns by multiple categorical factors (i.e., the working poor's sustainable trips and the working poor's trips by drive alone), so we were able to achieve a more in-depth understanding of trip patterns in the study area. The results showed that the working poor in Ramsey County were much more dependent on sustainable commuting and commuted to work mostly in the downtown area, whereas the working poor driving a car occupied more space and commuted a greater distance. Thus, more efficient commutes represent a significant quality of life factor for the urban poor when evaluating residential and employment opportunities in the central city.

Due to the COVID-19 pandemic, remote work has provided more options for residence locations and has generally resulted in less work stress being experienced. Thus, traffic congestion in the downtown area is obsolete in a pandemic situation. The question is whether telecommuting will likely continue to grow after the pandemic ends. Transportation planners and policymakers need to reshape the current transport system in a manner that results in less wasted commuting time, reduced energy consumption, and possibly more electric vehicles. It is worth noting that planners and policymakers take into consideration the opinions and concerns of those who use public transportation the most, i.e., the workers. According to Liu et al. (2020), the vast majority of commuting activity is undertaken by workers, and therefore, their opinions are very significant and are most useful in improving commuting efficiency [22].

This study has room for improvement. Future research can first address heterogenous trip data of different socio-economic groups (e.g., ethnicity, gender) in a similar urban context. Due to the baby boomer generation (born between 1946 and 1964), the older workers (65 and above) in the workforce will continue to grow, so it would be interesting to see how the aging baby-boomer population impacts our future transportation system. Second, the current approach investigated commuting trips based on a fixed period of time. It will be beneficial to study a close-up examination of the changing commuting patterns of 
different population groups in U.S. metro areas over time. Making data comparable across time would improve the quality of spatio-temporal analysis of urban commuting patterns.

Author Contributions: W.J. designed and guided the research, analyzed the data, and drafted the manuscript. F.Y. and J.J.L. contributed to the design, writing, and discussion of the paper. All authors have read and agreed to the published version of the manuscript.

Funding: This research received no external funding.

Institutional Review Board Statement: Not applicable.

Informed Consent Statement: Not applicable.

Data Availability Statement: The data that support the findings of this study are openly available in AASHTO at https:/ / ctpp.transportation.org/ (accessed on 1 February 2021), reference number [43].

Conflicts of Interest: The authors declare no conflict of interest.

\section{References}

1. Antipova, A.A. Analysis of Commuting Distances of Low-Income Workers in Memphis Metropolitan Area, TN. Sustainability 2020, 12, 1209. [CrossRef]

2. Kim, C.; Sang, S.; Chun, Y.; Lee, W. Exploring urban commuting imbalance by jobs and gender. Appl. Geogr. 2012, 32, 532-545. [CrossRef]

3. Jang, W.; Yao, X. Tracking Ethnically Divided Commuting Patterns Over Time: A Case Study of Atlanta. Prof. Geogr. 2014, 66, 274-283. [CrossRef]

4. Heath, Y.; Gifford, R. Extending the Theory of Planned Behavior: Predicting the Use of Public Transportation ${ }^{1}$. J. Appl. Soc. Psychol. 2002, 32, 2154-2189. [CrossRef]

5. Boto-Álvarez, A.; García-Fernández, R. Implementation of the 2030 Agenda Sustainable Development Goals in Spain. Sustainability 2020, 12, 2546. [CrossRef]

6. D'Adamo, I.; Rosa, P. How Do You See Infrastructure? Green Energy to Provide Economic Growth after COVID-19. Sustainability 2020, 12, 4738. [CrossRef]

7. Molina, J.A.; Giménez-Nadal, J.I.; Velilla, J. Sustainable Commuting: Results from a Social Approach and International Evidence on Carpooling. Sustainability 2020, 12, 9587. [CrossRef]

8. Bergman, Z.; Bergman, M.M. A Case Study of the Sustainable Mobility Problem-Solution Paradox: Motility and Access of Metrorail Commuters in the Western Cape. Sustainability 2019, 11, 2842. [CrossRef]

9. American Public Transport Association. Who Rides Public Transportation. 2017. Available online: https://community-wealth. org/sites/clone.community-wealth.org/files/downloads/who\%20rides\%20public\%20transportation.pdf (accessed on 5 January 2021).

10. Shaw, C.B.; Gallent, N. Sustainable Commuting: A Contradiction In Terms? Reg. Stud. 1999, 33, 274-280. [CrossRef]

11. Gojanovic, B.; Welker, J.; Iglesias, K.; Daucourt, C.; Gremion, G. Electric Bicycles as a New Active Transportation Modality to Promote Health. Med. Sci. Sports Exerc. 2011, 43, 2204-2210. [CrossRef] [PubMed]

12. Koglin, T.; Rye, T. The marginalisation of bicycling in Modernist urban transport planning. J. Transp. Heal. 2014, 1, $214-222$. [CrossRef]

13. Thuany, M.; Melo, J.C.N.; Tavares, J.P.B.; Santos, F.M.J.; Silva, E.C.M.; Werneck, A.O.; Dantas, S.; Ferrari, G.; Sá, T.H.; Silva, D.R. The Profile of Bicycle Users, Their Perceived Difficulty to Cycle, and the Most Frequent Trip Origins and Destinations in Aracaju, Brazil. Int. J. Environ. Res. Public Health 2020, 17, 7983. [CrossRef]

14. Moslem, S.; Campisi, T.; Szmelter-Jarosz, A.; Duleba, S.; Nahiduzzaman, K.M.; Tesoriere, G. Best-Worst Method for Modelling Mobility Choice after COVID-19: Evidence from Italy. Sustainability 2020, 12, 6824. [CrossRef]

15. Ajzen, I. The theory of planned behavior. Organ. Behav. Hum. Decis. Process. 1991, 50, 179-211. [CrossRef]

16. Peng, J.; Juan, Z.-C. The Theory of Planned Behavior: The Role of Descriptive Norms and Habit in the Prediction of Intercity Travel Mode Choice. J. Converg. Inf. Technol. 2013, 8, 211-219.

17. Lois, D.; Moriano, J.A.; Rondinella, G. Cycle commuting intention: A model based on theory of planned behaviour and social identity. Transp. Res. Part F Traffic Psychol. Behav. 2015, 32, 101-113. [CrossRef]

18. Chen, K.; Liang, H. Factors Affecting Consumers' Green Commuting. Eurasia J. Math. Sci. Technol. Educ. 2016, 12, 527-538. [CrossRef]

19. Chen, K.; Liang, H.; Wang, X. Psychological Divergence Between Urban and Suburban Chinese in Relation to Green Commuting. Soc. Behav. Pers. Int. J. 2016, 44, 481-498. [CrossRef]

20. Song, Y.; Shao, G.; Song, X.; Liu, Y.; Pan, L.; Ye, H. The Relationships between Urban Form and Urban Commuting: An Empirical Study in China. Sustainability 2017, 9, 1150. [CrossRef]

21. Gao, K.; Shao, M.; Sun, L. Roles of Psychological Resistance to Change Factors and Heterogeneity in Car Stickiness and Transit Loyalty in Mode Shift Behavior: A Hybrid Choice Approach. Sustainability 2019, 11, 4813. [CrossRef] 
22. Liu, C.; Cao, M.; Yang, T.; Ma, L.; Wu, M.; Cheng, L.; Ye, R. Inequalities in the commuting burden: Institutional constraints and job-housing relationships in Tianjin, China. Res. Transp. Bus. Manag. 2020, 100545. [CrossRef]

23. Fan, J.X.; Wen, M.; Kowaleski-Jones, L. An ecological analysis of environmental correlates of active commuting in urban U.S. Health Place 2014, 30, 242-250. [CrossRef]

24. Kim, C.; Choi, C. Towards Sustainable Urban Spatial Structure: Does Decentralization Reduce Commuting Times? Sustainability 2019, 11, 1012. [CrossRef]

25. Oviedo, D.; Guzman, L.A. Revisiting Accessibility in a Context of Sustainable Transport: Capabilities and Inequalities in Bogotá. Sustainability 2020, 12, 4464. [CrossRef]

26. Levin, L. How May Public Transport Influence the Practice of Everyday Life among Younger and Older People and How May Their Practices Influence Public Transport? Soc. Sci. 2019, 8, 96. [CrossRef]

27. Delbosc, A.; Currie, G. The spatial context of transport disadvantage, social exclusion and well-being. J. Transp. Geogr. 2011, 19, 1130-1137. [CrossRef]

28. Zhao, F.; Park, N. Using Geographically Weighted Regression Models to Estimate Annual Average Daily Traffic. Transp. Res. Rec. J. Transp. Res. Board 2004, 1879, 99-107. [CrossRef]

29. Chiou, Y.-C.; Jou, R.-C.; Yang, C.-H. Factors affecting public transportation usage rate: Geographically weighted regression. Transp. Res. Part A Policy Pr. 2015, 78, 161-177. [CrossRef]

30. Bai, T.; Li, X.; Sun, Z. Effects of cost adjustment on travel mode choice: Analysis and comparison of different logit models. Transp. Res. Procedia 2017, 25, 2649-2659. [CrossRef]

31. Hasnine, M.S.; Lin, T.; Weiss, A.; Habib, K.N. Determinants of travel mode choices of post-secondary students in a large metropolitan area: The case of the city of Toronto. J. Transp. Geogr. 2018, 70, 161-171. [CrossRef]

32. Liu, X.; Gao, L.; Ni, A.; Ye, N. Understanding Better the Influential Factors of Commuters' Multi-Day Travel Behavior: Evidence from Shanghai, China. Sustainability 2020, 12, 376. [CrossRef]

33. Ding, L.; Zhang, N. A Travel Mode Choice Model Using Individual Grouping Based on Cluster Analysis. Procedia Eng. 2016, 137, 786-795. [CrossRef]

34. Cheng, L.; Chen, X.; De Vos, J.; Lai, X.; Witlox, F. Applying a random forest method approach to model travel mode choice behavior. Travel Behav. Soc. 2019, 14, 1-10. [CrossRef]

35. Jing, P.; Zhao, M.; He, M.; Chen, L. Travel Mode and Travel Route Choice Behavior Based on Random Regret Minimization: A Systematic Review. Sustainability 2018, 10, 1185. [CrossRef]

36. Ganciu, A.; Balestrieri, M.; Imbroglini, C.; Toppetti, F. Dynamics of Metropolitan Landscapes and Daily Mobility Flows in the Italian Context. An Analysis Based on the Theory of Graphs. Sustainability 2018, 10, 596. [CrossRef]

37. Rademacher, N. How and where Minnesota's population grew in the last decade, StarTribune. 12 April 2020. Available online: https:/ / www.startribune.com/how-and-where-minnesota-s-population-grew-in-the-last-decade/569315761/ (accessed on 7 December 2020).

38. Minnesota Compass, Ramsey County data. Available online: https://www.mncompass.org/profiles/county/ramsey (accessed on 5 November 2020).

39. Ramsey County. 2040 Land Use Forecasts and Community Designation, Ramsey County Comprehensive Plan. Available online: https:/ / www.ramseycounty.us/sites/default/files/Departments/Policy\%20and\%20Planning/RamseyCounty2040_ Land\%20Use.pdf (accessed on 13 December 2020).

40. Yuan, F.; Sawaya, K.E.; Loeffelholz, B.C.; Bauer, M.E. Land cover classification and change analysis of the Twin Cities (Minnesota) Metropolitan Area by multitemporal Landsat remote sensing. Remote Sens. Environ. 2005, 98, 317-328. [CrossRef]

41. Minnesota Department of Transportation (MNDOT). Ramsey County Highway Map. Available online: https://web.archive.org/ web/20171230221457/http:/www.dot.state.mn.us/maps/gdma/data/maps/county/ramsey.pdf (accessed on 7 December 2020).

42. Ramsey County Public Works Department (RCPWD). Ramsey County Public Works Department $2017-2021$ Transportation Improvement Plan. Available online: https://web.archive.org/web/20171230214627/https:/www.ramseycounty.us/sites/ default/files/Roads\%20and\%20Transit/2017-2021\%20Transportation\%20Improvement\%20Program.pdf (accessed on 7 December 2020).

43. American Association of State Highway and Transportation (AASHTO). Available online: https://ctpp.transportation.org/ (accessed on 1 September 2020).

44. Brunsdon, C.; Fotheringham, A.S.; Charlton, M.E. Geographically Weighted Regression: A Method for Exploring Spatial Nonstationarity. Geogr. Anal. 1996, 28, 281-298. [CrossRef]

45. Horner, M.W.; Murray, A.T. Excess Commuting and the Modifiable Areal Unit Problem. Urban Stud. 2002, 39, 131-139. [CrossRef]

46. Sultana, S. Job/Housing Imbalance and Commuting Time in the Atlanta Metropolitan Area: Exploration of Causes of Longer Commuting Time. Urban Geogr. 2002, 23, 728-749. [CrossRef]

47. O'Kelly, M.E.; Lee, W. Disaggregate Journey-to-Work Data: Implications for Excess Commuting and Jobs-Housing Balance. Environ. Plan. A Econ. Space 2005, 37, 2233-2252. [CrossRef]

48. United States Census Bureau, Poverty Thresholds. 2016. Available online: https://www.census.gov/data/tables/time-series/ demo/income-poverty / historical-poverty-thresholds.html (accessed on 5 September 2020).

49. Yap, B.W.; Sim, C.H. Comparisons of various types of normality tests. J. Stat. Comput. Simul. 2011, 81, 2141-2155. [CrossRef] 
50. ACS Commuter Data Visualizations. 2016. Available online: http://ilikebigbytes.com/index.php/2016/05/18/acs-commuterdata-visualizations / (accessed on 30 December 2020).

51. Bureau of Transportation Statistics. National Transportation Statistics 2/27/2020 Updates, Principal Means of Transportation to Work and other categories. Available online: https:/ /www.bts.dot.gov/newsroom/national-transportation-statistics-02272020 (accessed on 10 October 2020).

52. Serulle, N.U.; Cirillo, C. Transportation needs of low income population: A policy analysis for the Washington D.C. metropolitan region. Public Transp. 2016, 8, 103-123. [CrossRef] 